\title{
ARTIGO
}

\section{FENÔMENOS DE MUDANÇA LINGUÍSTICA E ENSINO: UMA ABORDAGEM CENTRADA NO USO EFETIVO DA LÍNGUA}

\author{
Phenomena of language change and teaching: an approach centered \\ on the effective use of the language \\ Fenómenos de cambio linguístico y enseñanza: un enfoque centrado \\ en el uso efectivo de la lengua
}

Gessilene Silveira Kanthack

Universidade Estadual de Santa Cruz - Brasil

\section{Resumo}

Este artigo visa apresentar alguns casos de mudança linguística constatados a partir de uma metodologia que contempla usos efetivos da língua portuguesa. São casos que ilustram a chamada gramaticalização, um fenômeno de mudança linguística compreendido como um processo através do qual, itens ou construções lexicais, em determinados contextos linguísticos, assumem funções gramaticais, e, uma vez gramaticalizados, continuam a desenvolver novas funções gramaticais (HOPPER; TRAUGOTT, 1993). Esse tipo de mudança só pode ser compreendido a partir de uma concepção de língua como atividade real, um instrumento de interação social (NEVES, 1997). Logo, gramática não se resume a um produto fechado, estático; ela é dinâmica, com estruturas flexíveis e permeáveis às pressões do uso (CASTILHO, 2012). As amostras apresentadas evidenciam exatamente essa dinamicidade, revelada pela aplicação do princípio de exploração de velhas formas para novas funções. O reconhecimento desse tipo de princípio é necessário para a compreensão dos movimentos funcionais que operam no âmbito, por exemplo, das classes de palavras, um tema comumente abordado no contexto escolar, mas que não recebe um tratamento linguístico adequado.

Palavras-chave: Ensino. Mudanças. Uso.

\begin{abstract}
This paper aims to present some cases of language change verified from a methodology which contemplates effective uses of the portuguese language. These cases illustrate the so called grammaticalization, a phenomenon of language change understood as the process whereby
\end{abstract}


lexical items or constructions come in certain linguistic contexts to serve grammatical functions, and, once grammaticalized, they continue to develop new grammatical functions (HOPPER; TRAUGOTT, 1993). This kind of change can only be understood from a conception of language as a real activity, an instrument of social intervention (NEVES, 1997). So, grammar is not just limited to a closed product, static; it is dynamic, with flexible structures and permeable to pressures of use (CASTILHO, 2012). The presented samples highlight exactly this dynamicity, revealed by the application of the principle of exploitation of old forms for new functions. The recognition of this kind of principle is necessary for the understanding of functional movements which operate, for example, within word classes, a frequently discussed theme in the school context, but which still does not get a proper linguistic treatment.

Keywords: Teaching. Changes. Use.

\section{Resumen}

Este artículo busca presentar algunos casos de cambio linguístico constatados a partir de una metodología que contempla usos efectivos de la lengua portuguesa. Son casos que ilustran la denominada gramaticalización, un fenómeno de cambio linguístico comprendido como un proceso a través del cual ítems o construcciones lexicales, en determinados contextos lingüísticos, asumen funciones gramaticales, y una vez gramaticalizados asumen nuevas funciones gramaticales (HOPPER; TRAUGOTT, 1993). Este tipo de cambio solo puede ser comprendido a partir de una concepción de lengua como actividad real, un instrumento de interacción social (NEVES, 1997). Por lo tanto, la gramática no se resume a un producto cerrado, estático; es dinámica, con estructuras flexibles y permeables a las presiones del uso (CASTILHO, 2012). Las muestras presentadas evidencian exactamente ese dinamismo, revelado por la aplicación del principio de atribución de nuevas funciones a las viejas formas linguísticas. El reconocimiento de este tipo de principio es necesario para la comprensión de los movimientos funcionales que operan en el ámbito, por ejemplo, de las clases de palabras, un tema comúnmente tratado en el contexto escolar, pero que no se trabaja linguísticamente de forma adecuada.

Palavras clave: Enseñanza. Cambio. Uso.

\section{Introdução}

Que as línguas mudam com o tempo, é fato! Percebemos isso, por exemplo, ou comparando a fala de pessoas de diferentes faixas etárias ou entrando em contato com textos escritos ou falados de diferentes épocas. E por que a língua muda? Ela muda porque, segundo Coseriu (1979), nunca está pronta. A cada época, a cada geração, a cada situação de fala, a cada situação de escrita, o falante pode se apropriar de regras já existentes e movimentar o sistema da língua, recriando-a, inovando-a, já que ela está inteiramente a serviço da dinâmica social da qual os indivíduos fazem parte. 
Por natureza, a língua é dinâmica, heterogênea, um sistema que não está pronto, acabado, logo, a mudança é inevitável, impulsionada pela necessidade comunicativa dos falantes, que, no anseio de tornar a comunicação mais efetiva, de dar mais precisão ou expressividade ao que querem dizer, criam novas palavras, novas estruturas, novos sentidos, atribuem novas funções para formas já existentes, evidenciando, assim, a natureza maleável do sistema linguístico.

Essa propriedade, no entanto, nem sempre é reconhecida e abordada adequadamente no contexto escolar. Primeiro, pelo fato de nem todos os falantes, incluindo aí professores de língua portuguesa, aceitarem as mudanças de uma língua; segundo, pelo desconhecimento de metodologias que podem ser usadas para descrever e explicar os fenômenos de mudança.

Quanto à aceitação da mudança, por parte de muitos falantes, ela não ocorre por conta da concepção de língua assumida. Para muitos, língua corresponde a um sistema homogêneo, estável, representado por um tipo de gramática que fixa um conjunto de regras que devem ser seguidas. Nessa perspectiva, mudança implica desconforto, estranhamento, reações negativas, pois tudo o que foge ao modelo de língua estabelecido como ideal é visto como "erro", “defeito". Assim, a violação ou mudança no uso das regras de bem falar e escrever prescritas para a chamada norma culta da língua implica em julgamentos sociais que resultam num tipo de preconceito muito debatido atualmente, o preconceito linguístico, definido como o ato de discriminar um falante pelo modo de falar a sua língua.

Do ponto de vista da linguística, por sua vez, as diferenças de usos de uma língua não são avaliadas negativamente, são vistas como regulares, ordenadas, motivadas por diferentes fatores, podendo ser captadas por metodologias que viabilizam a compreensão do real funcionamento de uma língua. Dentre as metodologias utilizadas pelos linguistas, uma das que se destaca, atualmente, tem como foco o uso efetivo da língua, seguindo o princípio de que são as motivações pragmáticas que determinam a forma e a função das expressões linguísticas. Estas, portanto, só podem ser explicadas a partir do uso real a que elas se prestam nas situações de comunicação.

Reconhecendo que se trata de uma metodologia importante para compreender processos de mudança linguística, objetivamos, com este artigo, apresentar algumas amostras que evidenciam o fenômeno de mudança denominado de gramaticalização, coletadas em situações concretas de uso da língua portuguesa. Ao final, com base nas amostras apresentadas, pontuamos a necessidade de a escola reconhecer a atuação, na língua, do 
princípio de exploração de velhas formas para novas funções, um recurso que possibilita explicar os usos diversificados, por exemplo, das classes de palavras, um tema que ocupa um lugar de destaque nas aulas de língua portuguesa, mas que não é abordado adequadamente, por falta de uma descrição do funcionamento real das palavras e dos processos resultantes do uso da língua.

\section{Mudança linguística sob a perspectiva funcional: o uso da língua em foco}

Para captar a dinamicidade de uma língua, a perspectiva teórica denominada de Funcionalismo $^{1}$ considera fundamental recorrer à língua efetivamente em uso, pois entende que é na situação comunicativa, que envolve interlocutores, seus objetivos e o contexto discursivo, que se deve buscar a motivação para explicar os fatos da língua. Analisar a língua do ponto de vista funcional significa assumir que ela "desempenha funções que são externas ao sistema linguístico em si" e que "as funções externas influenciam a organização interna do sistema linguístico" (CUNHA 2008, p. 158). Função, nessa perspectiva, significa relação direta entre uma dada forma/estrutura e seu uso efetivo em situações de interação comunicativa.

Complementa essas premissas o postulado de que a língua é uma competência comunicativa e as estruturas linguísticas não são objetos autônomos. Quanto à competência comunicativa, ela é definida como a capacidade que os falantes têm de selecionar e usar satisfatoriamente os itens linguísticos. Isso decorre da noção de que a língua é um sistema funcional e adaptivo, que permite ao falante fazer escolhas apropriadas a seus interesses comunicativos. Nessa dinâmica, as estruturas linguísticas são, por natureza, flexíveis e estão sujeitas a reelaborações constantes (CASTILHO, 2012).

A gramática, compreendida como mecanismo geral que organiza as línguas, passa, então, a ser concebida não como uma estrutura fechada, completa, estática, mas como um fenômeno sociocultural, sendo suas estruturas e regularidades moldadas num processo contínuo, via repetição. Dada essa propriedade, uma gramática nunca está pronta, é um

\footnotetext{
${ }^{1}$ Funcionalismo reporta-nos à famosa Escola Linguística de Praga, designação atribuída a um grupo de estudiosos que começou a atuar antes de 1930, os quais defendiam a língua como um instrumento de interação social, opondo-se, assim, à chamada corrente formalista, cujos representantes concebiam a língua como objeto autônomo, dissociada do ato comunicativo (NEVES, 1997). A partir da década de 1970, o termo funcionalismo ganhou força nos Estados Unidos e, de lá para cá, inclusive no Brasil, muitas pesquisas que advogam uma linguística baseada no uso da língua já foram desenvolvidas.
} 
sistema adaptável, que está sempre em acomodação. Isso ocorre porque, sendo a língua um instrumento de interação verbal, o falante escolhe e decide o que vai ou não usar conforme as suas intenções comunicativas. Logo, as estruturas produzidas por ele não são vistas apenas como unidades que veiculam informações, mas também como escolhas que refletem as situações de interação social.

Nessa perspectiva, compreende-se que o uso diário de uma língua pode ocasionar adaptações de formas e funções. Sobre isso Tavares (2012, p. 35) explica:

[...] Como as experiências do falante e do ouvinte com a língua são particulares e podem ser distintas em diversos graus, eles têm de se esforçar para se fazer entender e para tentar entender, negociando e adaptando funções e formas para levar sua interação linguística adiante, o que instiga a mudança $[\ldots]$.

A propósito, a mudança é vista como algo natural, resultante das necessidades comunicativas dos falantes. Segundo Martelotta (2015, p. 61),

[...] as mudanças de uma língua devem ser compreendidas como movimentos que se iniciam no instante em que um indivíduo produz seu discurso para um interlocutor específico, em uma situação comunicativa determinada. Se por um lado a produção discursiva é limitada pelas restrições já consagradas na gramática da língua, por outro constitui um processo criativo no qual o falante recria formas e estende sentidos de acordo com suas limitações cognitivas e as necessidades comunicativas impostas contextualmente.

Assim, para depreender as funções que uma determinada forma/estrutura assume, é necessário, portanto, recorrer ao lócus da observação, a situação concreta de uso da língua, pois, como vimos nas palavras de Martelotta, é a situação comunicativa que impõe a movimentação funcional de uma língua. E é adotando esse tipo de metodologia que se pode explicar a gramaticalização, um fenômeno de mudança responsável pela constante renovação do sistema de uma língua.

\section{Gramaticalização: fenômeno de mudança linguística}

Considerada como um dos casos de mudança mais comuns nas línguas em geral, a gramaticalização é um fenômeno associado à necessidade constante de o falante ajustar as formas e as funções dos itens de uma língua. Introduzido pelo francês Antoine Meillet, em 1912, o termo gramaticalização foi usado, inicialmente, para explicar a passagem de uma 
palavra autônoma à função de elemento gramatical, uma trajetória de mudança firmada pela regularização do uso da língua (GONÇALVES et al, 2007).

Com o passar do tempo, os estudiosos da gramaticalização foram aperfeiçoando o conceito inicial de Meillet, tendo em vista a ampliação do campo dos fenômenos que poderiam ser explicados a partir dessa perspectiva de mudança. Dentre os estudiosos, destacam-se Hopper e Traugott (1993), que redefiniram gramaticalização como um processo através do qual, itens lexicais, em determinados contextos linguísticos, assumem funções gramaticais, e, uma vez gramaticalizados, continuam a desenvolver novas funções gramaticais. Itens lexicais correspondem a signos linguísticos plenos (como nomes, verbos, adjetivos), autônomos, que expressam uma significação mais concreta; já os itens gramaticais (como preposições, advérbios, verbos auxiliares, conjunções etc) são de natureza não autônoma, com valores abstratos, que formam unidades com outras categorias.

No que diz respeito à mudança categorial, do lexical para gramatical ou de gramatical para mais gramatical, ela não ocorre rapidamente, pode haver, inclusive, estágios de ambiguidade, quando uma determinada forma/estrutura pode pertencer a mais de uma categoria simultaneamente. A frequência com que as categorias ocorrem na comunidade de fala é que determinará se uma forma/estrutura passará ou não a desempenhar propriedades gramaticais.

A propósito, frequência de uso é considerada um dos mecanismos para atestar a gramaticalização. Vitral (2006, p. 155) explica que, se um determinado item estiver em processo de gramaticalização, a tendência é: “a) que sua frequência de uso aumente; b) que a sua frequência quando em função gramatical aumente; c) que a sua frequência quando em função lexical diminua". Esse tipo de mecanismo influencia diretamente na geração de uma mudança, pois fixa o novo uso, tornando-o regular, estável, no sistema da língua. Segundo Haiman (1994, apud CESÁRIO 2012, p. 25),

[...] a gramaticalização pode ser pensada como uma forma de rotinização da língua. Uma forma ou combinação de formas ocorre no discurso com frequência crescente e, começando como uma forma não usual de fazer ou reforçar um ponto no discurso, passa a ser um meio usual e não marcado de desempenhar esse papel. A frequência com que tais expressões ocorrem será um fator que determina se a forma passa ou não a ser considerada gramatical pela comunidade.

Para verificar a frequência de uso, é fundamental, portanto, adotar uma metodologia que leve em consideração o uso efetivo da língua. No intuito de ilustrar esse tipo de mudança, 
apresentamos, na próxima seção, algumas amostras de usos concretos da língua portuguesa, que colocam em evidência a aplicação de um dos princípios da gramaticalização: exploração de velhas formas para novas funções.

\section{Amostras de mudanças na língua portuguesa: em foco algumas classes de palavras}

Resultadas de pesquisas ${ }^{2}$ cujo foco foi o uso concreto da língua portuguesa, as amostras que apresentamos revelam que, num mesmo domínio funcional, uma mesma forma pode assumir mais de uma função, e, nessa dinâmica de uso, uma função original coexiste, naturalmente, com uma nova função. Vamos às amostras:

- dar: de verbo pleno a verbo suporte ${ }^{3}$

O verbo dar é classificado, tanto em gramáticas normativas quanto em dicionários da língua portuguesa, como pleno, de natureza transitiva, que veicula noção de transferência, como no exemplo (1):

(1) [...] obteve do Congresso, em troca do compromisso de [dar dinheiro público aos parlamentares], uma licença para desrespeitar a lei.

Como se pode perceber, o verbo dar manifesta o seu valor transferencial ao selecionar os objetos, direto (dinheiro) e indireto (aos parlamentares), cumprindo, assim, a sua função de verbo pleno, com propriedades lexicais. Esse comportamento, no entanto, não se observa nos usos registrados em (2) e (3):

(2) Na vida real, os governos federal e estaduais anunciarão obras de [dar água na boca].

\footnotetext{
${ }^{2}$ Com exceção da pesquisa com o advérbio em -mente, as outras pesquisas foram desenvolvidas juntamente com alunos do programa de pós-graduação em Letras: linguagens e representações. Outras dessa natureza estão sendo realizadas no âmbito da Iniciação Científica e do PROFLETRAS.

${ }^{3}$ Corpus analisado: textos de opinião publicados na revista VEJA, meses de Dezembro/2014 e Janeiro/2015 (cf. MOTA; KANTHACK, 2016)
} 
(3) Até hoje esse método [dá certo], seja com o futuro pedreiro, seja com o Doutorando.

Nesses dois casos, o verbo dar, esvaziado semanticamente, já que não ostenta a propriedade transferencial que vimos em (1), funciona como um suporte, pois só tem sentido na composição que se forma com os outros elementos: dar água na boca e dar certo.

- $\quad$ aí: de advérbio a item sequencializador ${ }^{4}$

Nas gramáticas de cunho normativo, o item aí é descrito, basicamente, como advérbio, podendo denotar espaço ou tempo, como ilustram respectivamente os exemplos em (4) e (5):

(4) Olha... hoje eu acho que a gente tem que torcer por eles... eles estão aí né... eles vão atender a população brasileira.

(5) Fazer esse trabalho... a gente precisa fazer com muita responsabilidade e com muita alegria também. E foi aí que eu comecei a pensar de uma forma que as crianças viessem para São Paulo se tratar do câncer (...)

Como se pode notar, em (4) o aí tem como referente o Brasil, pois o falante faz menção aos médicos cubanos que haviam chegado ao país. Já, em (5), faz referência ao momento em que o entrevistado pensou nas crianças com câncer. E em (6) e (7), que função estaria exercendo o aî?

(6) Em um ano atrás de repente surgiu o "Porta dos Fundos". Aí eu entrei pra "Grande Família” e aí eu estreei no cinema o primeiro longa. Aí veio "Meu Passado me condena", tudo no segundo semestre do ano passado...

(7) Ela ficava num penhasco, a Irina, e eu fazia um violinista que passava num navio tocando e via aquela moça linda, aí um dia eu peguei um botezinho ia pra ilha e ela tinha inimigos ali, e aí me jogaram no penhasco um dia e eu tinha que voltar desfigurado.

\footnotetext{
${ }^{4}$ Corpus analisado: entrevistas do Programa Marília Gabriela Entrevista, do canal GNT, veiculadas no ano de 2013 (MARQUES; KANTHACK, 2014).
} 
Percebemos que o aí indica uma sucessão de fatos, atuando como elemento sequencializador, articulador das informações. Trata-se de uma estratégia muito comum, principalmente na língua falada. Nesse caso, o aí exerce, basicamente, o papel de uma conjunção, função essa que, na tradição, é atribuída a outros itens da língua portuguesa.

- até: de preposição a recurso argumentativo ${ }^{5}$

Nas gramáticas normativas, comumente o até é classificado como preposição, com a função de relacionar dois termos oracionais, e, dessa relação, indicar movimento espacial (8) ou temporal (9):

(8) Levantou de um pulo, pegou suas coisas e dirigiu-se até o guichê. Devolveu a passagem e encaminhou-se para a saída.

(9) Dormi às 4 da madrugada, acordei às 7 da manhã, voltei a ler, dormi às 11 , acordei às 12 , comi algo de olho no livro e tornei a ler, até terminar ontem às 10 da manhã.

Nesses dois usos, o até veicula a noção de limite, até o guichê (espacial) e até às 10 da manhã (temporal), uma característica própria desse tipo de preposição. Já, em (10) e (11), notamos alterações de sentido:

(10) Há uma semana, comecei a ler "O Caçador de Pipas”. De cara, gostei do estilo do autor, da forma com que usava as palavras, e até como ele rodeava e rodeava para, enfim, chegar ao ponto.

Em (10), o falante expressa o seu gosto pelo estilo do autor do livro que está lendo e, para reforçar uma das características que lhe agrada, usa o até com valor de inclusão ${ }^{6}$.

\footnotetext{
${ }^{5}$ Corpus analisado: textos de blogs, coletados do software Blogger (www.blogspot.com), produzidos por homens e mulheres, de diferentes regiões da Bahia (ALVES; KANTHACK, 2013).

${ }^{6}$ Em algumas gramáticas normativas, há previsão desse valor de inclusão para o item até, no entanto, essa propriedade é tratada, normalmente, em seções à parte, como na das palavras denominadas de denotativas.
} 
...meu professor era enorme, era fã de academia, mas tocava as cordas com a delicadeza de um anjo. Parecia até que ele tinha nascido para aquilo, fazer o som ecoar nos nossos ouvidos e corações.

Ao apresentar o argumento "parecia até que ele tinha nascido para aquilo...", o falante cria, no leitor, a expectativa de que a habilidade de tocar como um anjo não era comum a uma pessoa de traços físicos fortes, fã de academia. Nesse caso, assim como em (10), o uso indica que o até funciona como um recurso argumentativo, para introduzir um argumento contrário (11) ou um argumento considerado mais forte (10).

- advérbio em -mente: de modo a modalizador ${ }^{7}$

Tradicionalmente, a maioria dos advérbios terminados em -mente figura na classe denominada de modo. Se considerarmos a definição básica apresentada ao advérbio nas gramáticas de orientação normativa (palavra que modifica verbo, adjetivo e advérbio), percebemos que o advérbio de modo é aquele que mais se aproxima desse postulado, pois sua característica básica é atuar como qualificador de uma ação, um processo ou um estado expressos num verbo ou num adjetivo. De fato, notamos essa atuação em (12) e (13):

(12) a. A aeronave desapareceu misteriosamente no trajeto de Kuala Lumpur... b. A economia vai sendo sucateada, como um transatlântico, afundando lentamente.

(13) a. Ele (Bento XVI) é extremamente tímido.

b. ...mostrou que L. permaneceu assustadoramente calmo.

Aqui, os advérbios estão exercendo a função de modificador, como preconizado na definição tradicional: de verbos (12), atuando como um qualificador da ação; e de adjetivos (13), atuando como intensificador do conteúdo expresso pela forma adjetival.

Mas, o que dizer dos casos abaixo?

\footnotetext{
${ }^{7}$ Corpus analisado: entrevistas das páginas amarelas e reportagens de Capa veiculadas pela Revista VEJA, no período de janeiro a junho de 2015 (KANTHACK, 2015).
} 
.... minha chefe de gabinete avisou que haviam ligado... pedindo a carta de demissão de todos os ministros. Obviamente ele estava querendo aguar minha saída...

O que entrou oficialmente nos cofres...foi o produto do roubo...

O representante ... tentou argumentar que a falta do balanço não significava necessariamente uma situação financeira ruim.

(17) Ele era a grande esperança do povo brasileiro. Mas, infelizmente, fechou os olhos para a corrupção.

Como se pode notar nesse conjunto de exemplos, os advérbios não se enquadram na definição preconizada tradicionalmente, tendo em vista que são usados como estratégia para explicitar a avaliação do falante sobre as informações contidas na asserção. Em (14), temos o advérbio obviamente exercendo a função de asseverador, indicando a certeza do falante de que alguém estava querendo aguar sua saída. Em (15), o advérbio oficialmente é usado para delimitar o âmbito da afirmação, digamos, é do ponto de vista oficial a afirmação de o que entrou nos cofres públicos foi o produto do roubo. Em (16), com o necessariamente, o efeito de sentido alcançado pelo falante indica que a situação financeira, por falta de um balanço, não implica, obrigatoriamente, em algo negativo. Em (17), infelizmente representa a reação emotiva do falante frente ao que enuncia, nesse caso, o seu domínio de atuação extrapola o limite da sentença, passando a incidir sobre o próprio falante.

Como dar conta, então, desses casos? Qual é a classe apropriada para esse tipo de advérbio? Autores como Castilho e Castilho (1993) e Neves (2000) os definem como modalizadores. Segundo Neves,

[...] os advérbios modalizadores compõem uma classe ampla de elementos adverbiais que têm como característica básica expressar alguma intervenção do falante na definição da validade e do valor de seu enunciado: modalizar quanto ao valor de verdade, modalizar quanto ao dever, restringir o domínio, definir a atitude e, até, avaliar a própria formulação linguística. (NEVES, 2000, p. 244). 
Modalizar, na perspectiva funcional, significa direcionar para o interlocutor o ponto de vista do locutor (aquele que fala ou escreve) a respeito do que diz. Ao usar o advérbio em mente como modalizador, o falante expressa o tipo de comprometimento que assume em relação ao que está sendo apresentado no conteúdo proposicional.

\section{Dos usos: a confirmação da gramaticalização}

Das amostras analisadas, constatamos usos velhos e novos. Nos velhos, os itens linguísticos apresentam propriedades consideradas prototípicas: verbo dar, em sua função plena, se caracteriza como verbo transitivo, por selecionar dois objetos; aí, na função de advérbio, apresenta traços concretos, de espaço-tempo; até, enquanto preposição, denota valor de limite espacial-temporal; advérbio em - mente, como qualitativo, exerce a função de modo.

Nos novos usos, os itens evidenciam mudanças de propriedades categoriais: o verbo dar, como suporte, deixa de ser lexical e passa a ser gramatical, pois, como o próprio nome diz, atua como apoio a outro item linguístico (dar $\rightarrow$ água na boca e dar $\rightarrow$ certo); o aí, como sequencializador, deixa de ser um item autônomo e passa a ter um status gramatical; o até, como recurso argumentativo, perde as propriedades gramaticais e assume funções discursivas; o advérbio em -mente, com a função de modalizador, refletindo um posicionamento avaliativo do falante, exerce um valor intersubjetivo no discurso ${ }^{8}$.

Essas mudanças de propriedades confirmam, portanto, a gramaticalização, atestada assim: de lexical para gramatical, temos o caso do verbo dar; de gramatical para mais gramatical ainda, temos os casos com os itens aí, até e os terminados em -mente. Essas novas funções, conforme constatado nas pesquisas, convivem naturalmente com as funções já existentes, não implicando, necessariamente, no desaparecimento da antiga. Esse tipo de convivência caracteriza o que Hopper (1991) denomina de divergência: formas etimologicamente iguais que desempenham funções diferentes. Essa é a dinâmica da língua, que permite ao falante recorrer a uma forma/estrutura já existente e atribuir, dadas as necessidades comunicativas, novas "roupagens", isto é, novas funções. Temos, desse modo, a confirmação da aplicação do princípio da exploração de velhas formas para novas funções.

\footnotetext{
${ }^{8}$ Vale lembrar aqui que o advérbio em - mente, na função de modo, é fruto de um processo de gramaticalização: mente, sufixo formador de advérbio, um elemento -gramatical, derivou do substantivo mente, um elemento lexical. Na língua, tanto o substantivo quanto o sufixo co-ocorrem naturalmente.
} 
Como demonstramos, as funções, velhas e novas, estão sendo verificadas num mesmo domínio funcional, num mesmo recorte de tempo, por isso, é preciso esclarecer que a gramaticalização ilustrada está em curso. Se, a partir de um determinado momento, o falante fixar apenas as funções inovadoras em sua gramática, aí, sim, teremos efetivada a gramaticalização. E, como um processo natural, novamente, iniciam-se outras mudanças.

\section{Das mudanças linguísticas ao ensino: a classe de palavras em questão}

Quando se fala em ensino de mudanças linguísticas, o questionamento que surge é: como dar conta desse tema se, normalmente, o instrumento de ensino utilizado para abordar língua é a gramática normativa? Aquela que, segundo Travaglia (2000, p. 30-31), dita “normas para a 'correta' utilização oral e escrita do idioma, prescreve o que se deve e o que não se deve usar na língua [...] considera apenas uma variedade da língua como válida, como sendo a língua verdadeira”. Nas palavras de Possenti (1998, p. 64-65), trata-se de um manual que apresenta "um conjunto de regras, relativamente explícitas e relativamente coerentes, que, se dominadas, poderão produzir como efeito o emprego da variedade padrão (escrita e/ou oral)".

É fato que, na nossa tradição escolar, vigora essa concepção de gramática. Nela, não há lugar para heterogeneidade, para mudanças, inovações, pois "contempla apenas aqueles usos considerados aceitáveis na ótica da língua prestigiada socialmente" (ANTUNES, 2007, p. 30). Nessa perspectiva de tratamento da língua, as recomendações de uso das regras seguem razões históricas, convenções sociais que determinam o modelo ideal de língua: a norma culta.

Se for esse o modelo adotado, ao ensinar as classes de palavras, verbo, preposição, advérbios, por exemplo, o professor encontrará definições bastante homogêneas, uniformes, com o pressuposto de que as classes são fechadas, que não permitem deslizamentos funcionais, como os que demonstramos em nossas amostras. Se o professor tiver em mente que as classes são fechadas, ele não dará conta de explicar os usos diversificados que os falantes fazem das formas/estruturas linguísticas.

Sobre essa problemática, Ilari et al. (1991) reconhecem os limites imprecisos que envolvem os critérios tradicionais de classificação das palavras, alertando que, na prática, 
defrontamo-nos com inúmeros casos que não se aplicam aos critérios estabelecidos. Perini (1996, p. 319) também comenta sobre a questão:

[...] as classes tradicionais não são estabelecidas segundo critérios de coerência e relevância gramatical [...] a classificação tradicional tem pouca utilidade para a descrição. Algumas classes são razoavelmente bem estabelecidas, mas nenhuma é bem definida; e as definições não costumam ter nada a ver com as classes propriamente ditas. A maioria das classes tradicionais não fazem sentido em termos de descrição da língua.

Fazer sentido, nas palavras de Perini, significa dizer que as definições apresentadas não contemplam os usos efetivos das palavras. Desse modo, entendemos que não se pode adotar apenas o que está posto tradicionalmente para explicar o funcionamento das classes de palavras. Partilhamos, com Neves (2012, p. 83), a ideia de que se deve

[...] olhar as entidades da língua de um modo que não reconheça fluidez no estabelecimento e na definição de categorias, mas, mais do que isso, que ponha como foco os deslizamentos categoriais e suas implicações. Isso implica aceitar esses deslizamentos, sim, como perturbadores das sistematizações rígidas, mas, ao mesmo tempo, significa avaliá-los como garantidores de uma proposição mais fiel e segura, mais real e sustentável do sistema da língua, em cada momento de sua organização e/ou reorganização.

Em outras palavras, devemos reconhecer que o sistema de uma língua permite que o falante promova mudanças categoriais, alterações nas funções das formas. Assim, para um tratamento sistemático das classes de palavras, o professor deve complementar a abordagem tradicional adotando uma metodologia que contemple os usos efetivos de uma língua, pois é na situação comunicativa que as palavras adquirem suas funções, seus sentidos. A propósito da relação entre classe e função, Neves (2012, p. 206) esclarece:

[...] apontar uma estreita relação entre classes e funções não significa pleitear que a cada classe corresponda exatamente uma função, e vice-versa. Pelo contrário, a indicação central é a de que não há relação biunívoca (um a um) entre classes e funções, mas há fluidez de delimitações, há deslizamentos categoriais e há superposições funcionais, tudo a compor um aparato aberto à criação infinita de sentidos e de efeitos pelo uso da palavra.

Assumindo pressupostos como esses, ao ensinar classes de palavras, o professor deve deixar claro que o comportamento funcional de cada uma delas nem sempre se esgota na estrutura da oração; que as palavras podem exercer outras funções além daquelas consideradas prototípicas; que as funções (velhas ou novas) exercidas pelas formas refletem 
escolhas apropriadas do falante no ato comunicativo; que os usos, inovadores ou não, podem ser descritos e analisados do ponto de vista linguístico.

Assim, para explicar os velhos e novos usos, o professor pode recorrer a diferentes corpora, constituídos a partir de diferentes gêneros textuais, de língua falada ou escrita, que representem maior ou menor grau de formalidade, e montar amostras que possibilitem ao aluno apreender deslizamentos funcionais que envolvem palavras da língua portuguesa. Se o objetivo for perceber o percurso diacrônico de uma mudança, o professor pode utilizar textos de diferentes épocas; se for para diagnosticar usos diversificados, padrões recorrentes, pode buscar textos de uma mesma sincronia, isto é, de um mesmo intervalo de tempo.

$\mathrm{Na}$ investigação, o professor deve orientar os alunos no sentido de captar as movimentações e as expansões funcionais que envolvem os itens linguísticos em uso. Para tanto, pode: fazer levantamento de palavras que exercem funções variadas; analisar as restrições comportamentais e agrupar as palavras conforme as funções sintático-semânticas exercidas; observar quais usos são mais regulares, mais frequentes, se são os inovadores ou não; verificar se as regularidades do uso apontam ou não para um processo de mudança; enfim, ajudar o aluno a perceber a maleabilidade e flexibilidade do sistema linguístico.

Feito isso, o professor deve ainda conscientizar o aluno de que as inovações não devem ser vista como defeitos, mas como regras sistemáticas da própria língua; de que julgamentos sociais são atribuídos às variantes que não fazem parte do modelo idealizado como padrão-culto, de modo a orientá-lo a fazer as escolhas conscientes. Por conta do prestígio social que a escrita tem em nossa cultura, o professor deve apresentar ao aluno as formas e funções que são tidas como conservadoras, mas reconhecendo que as inovadoras também têm sua importância, seja em língua falada, seja em língua escrita, seja em estilo mais monitorado, seja em estilo menos monitorado. Afinal, todas fazem parte do sistema linguístico!

\section{Considerações finais}

Com o objetivo de tratar a questão da mudança linguística, um tema que não é abordado adequadamente no contexto escolar, apresentamos, neste artigo, resultados de algumas mudanças envolvendo classes de palavras da língua portuguesa, captadas a partir de uma metodologia que contempla usos efetivos da língua. 
Adotar esse tipo de abordagem significa assumir que a linguagem é um instrumento de comunicação e interação verbal, e que a gramática de uma língua se constitui num conjunto de escolhas formuladas pelo falante para atender seus propósitos comunicativos. Nesse intuito, o falante pode recorrer a formas e estruturas já existentes e fazer ajustes, adaptações, criar e recriar, já que elas são flexíveis, dinâmicas. Isso explica o fenômeno de mudança que exemplificamos, a gramaticalização, compreendida como um processo em que itens ou construções lexicais se tornam gramaticais, ou se já são gramaticais se tornam mais gramaticais ainda.

Com as amostras apresentadas, evidenciamos a dinamicidade que caracteriza, por exemplo, classes de palavras, comumente abordadas, nos manuais normativos, como classes fechadas, com o pressuposto de que as palavras assumem funções bem definidas: dar é um verbo de natureza transitiva, por selecionar objeto direto e indireto; aí é advérbio, por denotar lugar e tempo; até é preposição, por atuar na relação entre os termos oracionais; advérbio terminado em -mente é advérbio de modo, por exercer uma relação com a palavra que modifica: verbo ou adjetivo.

Não podemos, é claro, deixar de reconhecer a importância da descrição que uma gramática normativa apresenta, afinal, seu modelo contempla determinados usos. Enquanto instrumento normativo, ela não tem a pretensão de dar conta de todos os usos, de todas as funções que as palavras podem exercer numa língua. Cabe ao professor, no processo de ensino, reconhecer a realidade da língua e conduzir a reflexão sobre seu funcionamento, explicando ao aluno que há princípios que regulam o uso das palavras, que podem ou não se enquadrar no padrão estabelecido por uma gramática normativa. Os novos usos, que também estabelecem padrões, se constituem em diferentes escolhas por parte dos falantes para atender às diferentes situações comunicativas.

Portanto, as mudanças que são implementadas numa língua não podem ser vistas como irregulares, mas como escolhas apropriadas feitas pelo falante na tentativa de obter êxito no processo de interação verbal. É papel do professor refletir sobre essas questões, no sentido de promover no aluno a compreensão da natureza dinâmica e funcional de uma língua.

\section{Referências}

ALVES, Geliane Fonseca; KANTHACK, Gessilene Silveira. A multifuncionalidade do item até em blogs baianos: um caso de gramaticalização? In: IV SIMPÓSIO MUNDIAL DE LÍNGUA PORTUGUESA. 2013. Goiânia. Brasil. Anais do IV Simelp. Goiânia: Faculdade 
de Letras/UFG. 2013, p. 1869-1875. Disponível em:

<http://www.simelp.letras.ufg.br/anais/simposio_42.pdf> Acesso em: 05 fev. 2017.

ANTUNES, Irandé. Muito além da gramática: por um ensino de línguas sem pedras no caminho. São Paulo: Parábola Editorial, 2017.

CASTILHO, Ataliba Teixeira de; CASTILHO, Célia Maria Moraes de. Advérbios

Modalizadores. In: ILARI, Rodolfo. (Org.). Gramática do Português Falado: Vol. II: Níveis de Análise Lingüística. Campinas, SP: Editora da UNICAMP. 1993. p. 213-260.

CASTILHO, Ataliba Teixeira de. Funcionalismo e gramáticas do português brasileiro. In: SOUZA, Edson Rosa de (Org.) et. al. Funcionalismo linguístico: novas tendências teóricas. São Paulo: Contexto, 2012. p. 17-42.

CEZARIO, Maria Maura. Efeitos da criatividade e da frequência de uso no discurso e na gramática. In: SOUZA, Edson Rosa de (Org.) et al. Funcionalismo linguístico: análise e descrição. São Paulo: Contexto, 2012. p. 19-32.

COSERIU, Eugênio. Sincronia, diacronia e história: o problema da mudança linguístca. Rio de Janeiro/São Paulo: Presença/Edusp, 1979.

CUNHA, Maria Angélica Furtado da. Funcionalismo. In: MARTELOTTA, Mário Eduardo. (Org.). Manual de linguística. São Paulo: Contexto, 2008. p. 157-175.

GONÇALVES, Sebastião Carlos Leite et al. Tratado geral sobre gramaticalização. In:

GONÇALVES, Sebastião Carlos Leite Sebastião Carlos Leite; LIMA-HERNANDES, Maria Célia; CASSEB-GALVÃO, Vânia Cristina (Orgs.). Introdução à gramaticalização: princípios teóricos e aplicação. São Paulo: Parábola, 2007. p. 15-66.

HOPPER, Paul. One Some Principles of Grammaticalization. In: TRAUGOTT, Elisabeth Closs; HEINE, Bernd. Approaches to Grammaticalization. Amsterdã: Jonh Benjamins, 1991.

HOPPER, Paul; TRAUGOTT, Elisabeth Closs. Grammaticalization. Cambridge: Cambridge University Press, 1993.

ILARI, Rodolfo et al. Considerações sobre a posição dos advérbios. In: CASTILHO, Ataliba Teixeira de. (Org.). Gramática do português falado: V. I: A Ordem. 2. ed. Campinas, SP: Editora da UNICAMP/FAPESP, 1991. p. 63-141.

KANTHACK, Gessilene Silveira. Advérbios em -mente na língua portuguesa: análise de propriedades sintático-semânticas. In: V SIMPÓSIO MUNDIAL DE LÍNGUA PORTUGUESA. 2015. Lecce. Itália. Anais do V Simelp. Lecce: Università Del Salento. 2015. (No prelo).

MARQUES, Renata Moreira; KANTHACK, Gessilene Silveira. os usos do item aí no gênero entrevista: evidências de gramaticalização? Revista de Letras Dom Alberto. Santa Cruz do 
Sul/RS: Faculdade Dom Alberto. v. 1, n. 6, p. 258-276, 2014. Disponível em: <http://domalberto.ning.com/page/rlda-06-artigos > Acesso em: 05 fev. 2017.

MARTELOTTA, Mário Eduardo. A mudança linguística. In: CUNHA, Maria Angélica Frutado da; OLIVEIRA, Mariangela Rios de; Martelotta, Mário Eduardo (Orgs.). Linguística Funcional: teoria e prática. São Paulo: Parábola Editorial, 2015. p. 49-61.

MOTA, Nahendi Almeida; KANTHACK, Gessilene Silveira. Os usos funcionais do verbo "dar": Um caso de gramaticalização? Revista Tabuleiro de Letras. Salvador, UNEB, v. 10, n. 2, p. 90-103, 2016. Disponível em:

<https://www.revistas.uneb.br/index.php/tabuleirodeletras/issue/view/179> Acesso em: 05 fev. 2017.

NEVES, Maria Helena Moura. Gramática funcional. São Paulo: Martins Fontes, 1997.

NEVES, Maria Helena Moura. Gramática de usos do português. São Paulo: UNESP, 2000.

NEVES, Maria Helena Moura. A gramática passada a limpo: conceitos, análises e parâmetros. São Paulo: Parábola Editorial, 2012.

PERINI, Mário Alberto. Gramática descritiva do português. São Paulo: Ática, 1996.

POSSENTI, Sírio. Por que (não) ensinar gramática na escola. Campinas: Mercado de Letras, 1998.

TAVARES, Maria Alice. Gramática emergente e o recorte de uma construção gramatical. In: SOUZA, Edson Rosa de (Org.) et al. Funcionalismo linguístico: análise e descrição. São Paulo: Contexto, 2012. p. 33-51.

TRAVAGLIA, Luiz Carlos. Gramática e interação: uma proposta para o ensino de gramática no $1^{\circ}$ e $2^{\circ}$ graus. 5. ed. São Paulo: Cortez, 2000.

VITRAL, Lorenzo. O papel da frequência na identificação de processos de gramaticalização. Scripta. Belo Horizonte: PUC/Minas. V. 9, n. 18, p. 149-177, 2006. Disponível em: $<$ http://periodicos.pucminas.br/index.php/scripta/article/view/12599> Acesso em: 05 fev. 2016.

$D r^{a}$ Gessilene Silveira Kanthack

Universidade Estadual de Santa Cruz - Brasil

Mestrado em Letras: Linguagens e Representações Mestrado Profissional em Letras em Rede Nacional (PROFLETRAS) Grupo de Pesquisa: Linguagens, estruturas e práticas sociais E-mail: gskanthack@yahoo.com.br

Recebido em: 30 de novembro de 2016 Aprovado em: 21 de dezembro de 2016 